\title{
SPONTANEOUS RECTUS SHEATH HEMATOMA ASSOCIATED WITH LOW DOSE OF ACETYLSALICYLIC ACID
}

\author{
Hematoma espontâneo do músculo reto abdominal associado à baixa dose de ácido acetilsalicílico \\ André WATANABE, Diogo Borges PEDROSO, Fernando Marcus Felippe JORGE, \\ Túlio Marcos Rodrigues da CUNHA, Aloísio Fernando SOARES
}

From the Divisão de Cirurgia Geral, Hospital Regional da Asa Norte (Division of General Surgery, Asa Norte Regional Hospital), Brasília, DF, Brazil.

\section{Correspondence: \\ André Watanabe \\ E-mail: andreluiswatanabe@yahoo.com.br}

Financial source: none

Conflicts of interest: none

Received for publication: 18/09/2012

Accepted for publication: 19/06/2013

\section{INTRODUCTION}

$\mathrm{R}$ ectus sheath hematoma is an uncommon and frequently misdiagnosed cause of acute abdominal pain ${ }^{3}$. Although the exact incidence is unknown, Klingler et al. ${ }^{6}$ observed 23 cases (1.8\%) of rectus sheath hematoma among 1257 patients evaluated by ultrasound for acute abdominal disorders. It is defined as spontaneous in patients without history of abdominal trauma. In these cases, anticoagulation therapy is considered an important predisposing factor. Many series have described the association between spontaneous rectus sheath hematoma and anticoagulant agents, especially warfarin and heparin ${ }^{1,3,9}$. However, there are few reports of spontaneous rectus sheath hematoma occurring in patients exclusively on antiplatelet medications, such as acetylsalicylic acid. The authors report a case of spontaneous rectus sheath hematoma in a patient on low dose of acetylsalicylic acid.

\section{CASE REPORT}

A 62-year-old woman presented to the emergency department with a 12-hour history of a sudden onset abdominal pain in the left lower quadrant after an episode of sneeze. The pain increased gradually and a mass in the left lower quadrant was noted 30 minutes after the initial pain. Her past medical history included obesity, hypertension, coronary artery disease and diabetes. She was on captopril, glibenclamide and low dose of acetylsalicylic acid (100 mg daily). She had no trauma history and denied fever, nausea, vomiting, cough or any change in urinary output. Stool passage was as usual.
On clinical examination, she was talking comfortably and her vital signs were stable. Abdominal palpation revealed a tender, firm and non-pulsatile mass in the left lower quadrant. No rebound tenderness was reported. Laboratory evaluation revealed a hemoglobin level of $12.1 \mathrm{~g} / \mathrm{dL}$, a hematocrit of $36.6 \%$, a white cell count of $15.700 / \mathrm{mm}^{3}$ and a platelet count of $259.000 /$ $\mathrm{mm}^{3}$. Activated partial thromboplastin time (aPTT) and international normalized ratio (INR) were within normal limits. Chest and abdominal $x$-rays were unremarkable. An intra-abdominal neoplasm was suspected and the patient was admitted for further investigation.

One day after admission, physical examination revealed ecchymosis on the lower abdominal quadrants (Figure 1). The hemoglobin level dropped slightly to 11.8 $\mathrm{g} / \mathrm{dL}$ and her vital signs remained stable. A computed tomography scan of the abdomen was performed which showed a left-sided rectus sheath hematoma measuring $7.0 \times 9.5 \mathrm{~cm}$, without extension into the peritoneal cavity (Figure 2). A conservative treatment was adopted with immediate discontinuation of acetylsalicylic acid, complete bed rest and analgesia. No blood transfusion was required. The patient was discharged after a followup of 48 hours in the surgical ward. Her subsequent recovery was uneventful and acetylsalicylic acid was safely reintroduced seven days later. Outpatient abdominal ultrasound demonstrated the complete resolution of the hematoma 30 days after the diagnosis.

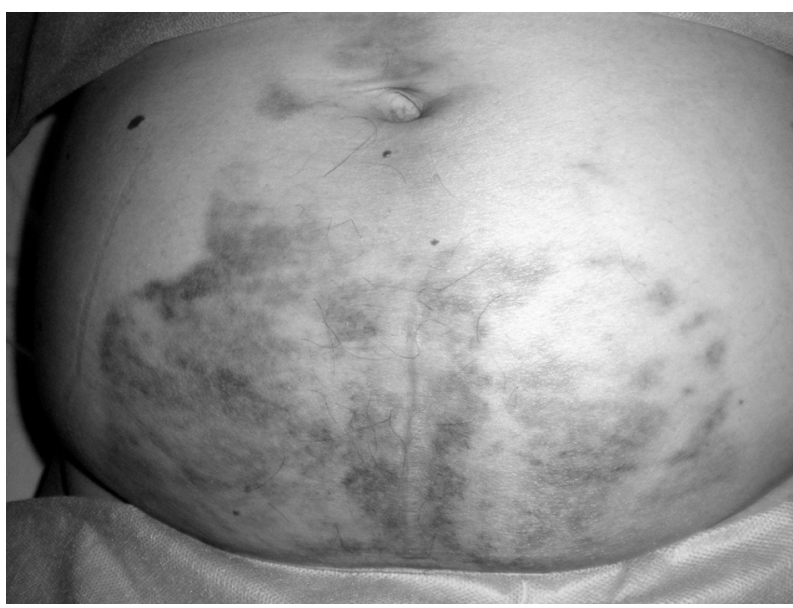

FIGURE 1 - Ecchymosis on the lower abdomen 


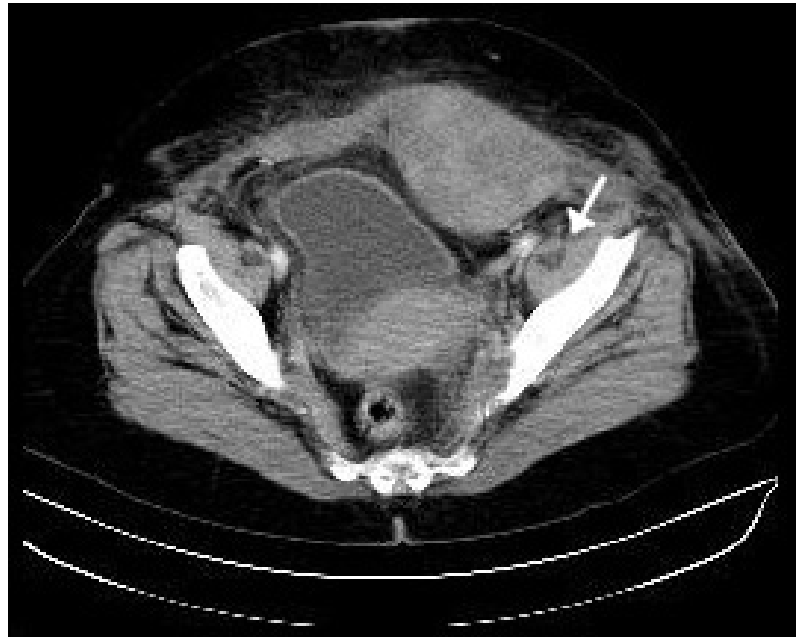

FIGURE 2 - Computed tomography image of the left-sided rectus sheath hematoma (arrow)

\section{DISCUSSION}

Rectus sheath hematoma is a well documented but rare clinical condition ${ }^{8}$. It is caused by an accumulation of blood into the rectus sheath, secondary to either epigastric vessel tear or direct rupture of the rectus muscle's fibers. Unnoticed trauma is considered one of the possible causes for spontaneous rectus sheath hematoma ${ }^{1}$. A vigorous contraction of the rectus muscle during defecation or cough may generate enough shear force to damage the muscle itself or tear the epigastric vessels that run between the posterior aspect of the muscle and the rectus sheath. In the study by Cherry et al. ${ }^{2}, 29 \%$ of the 126 patients with rectus sheath hematoma had a history of cough around the time of the diagnosis. In our patient, sneezing was apparently an important precipitating factor.

Anticoagulation is a known risk factor for rectus sheath hematoma. The widespread use of this therapy is believed to be a potential reason for the increased reporting of spontaneous rectus sheath hematoma ${ }^{1}$. In a review of 126 cases of rectus sheath hematoma, almost $70 \%$ of the patients were on anticoagulation therapy, while $24 \%$ of them were on simultaneous anticoagulation and antiplatelet therapies ${ }^{2}$. However, only $6 \%$ of the patients were on antiplatelet therapy alone, as in this case. In fact, antiplatelet medications are associated with a lower risk of bleeding complications than anticoagulant agents.

Rectus sheath hematoma occurs more frequently in women in the $6^{\text {th }}$ and $7^{\text {th }}$ decades of life ${ }^{2}$. This sex disparity is probably due to the presence of a larger rectus muscle mass in men, which provides protection against muscle and vessel injury ${ }^{4}$. The high incidence observed in elderly patients may be related to the increased use of anticoagulant agents among this population. Furthermore, rectus sheath hematoma is more commonly seen in the lower abdomen. In a recent series, $70 \%$ of the cases occurred in the lower segments of the abdominal wall9. The absence of a posterior aponeurosis below the arcuate line probably leaves the blood vessels in this area more vulnerable to injuries ${ }^{2}$.

Acute abdominal pain associated with a palpable abdominal mass is an important finding for the diagnosis. On clinical examination, Fothergill's sign is useful to distinguish an intra-abdominal mass from that arising in the abdominal wall. In patients with rectus sheath hematoma, the abdominal mass remains palpable when the patient tenses the anterior abdominal wall musculature by lifting the head while lying in a supine position ${ }^{5}$. This simple maneuver could be used in our patient avoiding delay in the diagnosis. Abdominal wall ecchymosis is present in only $17 \%$ of the cases and indicates intraperitoneal rupture or extraperitoneal extension of the hematoma ${ }^{2,8}$.

Both ultrasonography and CT scan have reduced unnecessary surgery in rectus sheath hematoma ${ }^{7}$. However, the CT is the diagnostic modality of choice. In two recent series of rectus sheath hematoma, it has established the diagnosis in $100 \%$ of the cases $^{4,9}$. In addition, the CT can exclude other abdominal disease if the diagnosis is not initially clear ${ }^{3}$.

Rectus sheath hematoma is usually self-limited and conservative management is feasible in most cases $^{8,9}$. Bed rest, analgesia and discontinuation of anticoagulant therapy are important aspects of supportive care ${ }^{4}$. Blood transfusion is indicated in the presence of hemodynamic compromise or substantial fall in hemoglobin ${ }^{1}$. When conservative treatment fails, endovascular embolization or surgery for the evacuation of the hematoma and ligation of the bleeding vessel should be considered ${ }^{8}$. Finally, rectus sheath hematoma is rarely fatal, with a reported overall mortality of $1.6 \%^{2}$.

\section{REFERENCES}

1. Alla VM, Karnam SM, Kaushik M, Porter J. Spontaneous rectus sheath hematoma. West J Emerg Med. 2010;11(1):76-9.

2. Cherry WB, Mueller PS. Rectus sheath hematoma: review of 126 cases at a single institution. Medicine (Baltimore). 2006;85(2):105-10.

3. Donaldson J, Knowles CH, Clark SK, Renfrew I, Lobo MD. Rectus sheath haematoma associated with low molecular weight heparin: a case series. Ann R Coll Surg Engl. 2007;89(3):309-12.

4. Fitzgerald JE, Fitzgerald LA, Anderson FE, Acheson AG. The changing nature of rectus sheath haematoma: case series and literature review. Int J Surg. 2009;7(2):150-4.

5. Fothergill WE. Haematoma in the abdominal wall simulating pelvic new growth. Br Med J. 1926;1(3413):941-2.

6. Klingler PJ, Wetscher G, Glaser K, Tschmelitsch J, Schmid T, Hinder RA. The use of ultrasound to differentiate rectus sheath hematoma from other acute abdominal disorders. Surg Endosc. 1999;13(11):1129-34.

7. Moreno Gallego A, Aguayo JL, Flores B, Soria T, Hernández Q, Ortiz S, González-Costea R, Parrilla P. Ultrasonography and computed tomography reduce unnecessary surgery in abdominal rectus sheath haematoma. Br J Surg. 1997;84(9):1295-7.

8. Salemis NS. Spontaneous rectus sheath hematoma presenting as acute surgical abdomen: an important differential in elderly coagulopathic patients. Geriatr Gerontol Int. 2009;9(2):200-2.

9. Salemis NS, Gourgiotis S, Karalis G. Diagnostic evaluation and management of patients with rectus sheath hematoma. A retrospective study. Int J Surg. 2010;8(4):290-3. 